\title{
La cadena de valor en la productividad de las microempresas, pequeñas empresas y medianas empresas en el contexto de la COVID-19
}

\author{
The value chain in productivity of micro, small, and \\ medium-sized enterprises (MSMEs) amid the COVID-19
}

\begin{abstract}
RESUMEN
La cadena de valor está conformada por las actividades que crean valor agregado para transformar un producto o servicio en creación de valor y comprende desde su producción hasta su comercialización. De esta manera, el análisis de la cadena de valor en una empresa permite realizar un diagnóstico situacional en cuanto a la capacidad de generación de valor para la empresa. En consecuencia, podría afirmarse que la cadena de valor constituye la piedra angular de la productividad y también es considerada como una herramienta estratégica en la gestión de las empresas a fin de que estas logren una ventaja competitiva, optimizando sus recursos y actividades para lograr el posicionamiento de la empresa en el mercado. Este ensayo analiza la cadena de valor como una oportunidad en el entorno y contexto del COVID-19 y presenta los fundamentos teóricos y reflexiones que pueden ser aplicados en cualquier tipo de empresa sin importar la dimensión que esta pueda tener.
\end{abstract}

Palabras Clave: Cadena de valor; productividad, COVID-19.

\begin{abstract}
The value chain is made up of value-added activities to transform a product or service into value creation and ranges from its production to its commercialization. Thus, the analysis of the value chain in a company allows a situational diagnosis of the capacity to generate value for the company. Therefore, it could be argued that the value chain is the cornerstone of productivity. Likewise, it is a strategic tool in the management of companies in order to achieve a competitive advantage, optimizing their resources and activities to achieve its market positioning. This essay analyzes the value chain as an opportunity in the environment and amid COVID-19. Theoretical foundations and reflections are presented that can be applied in any type of company regardless of the size it may have.
\end{abstract}

Keywords: Value chain; productivity; COVID-19.

\section{Teresa Jesús Rios Delgado}

triosd@unmsm.edu.pe ORCID: https://orcid.org/00000002-7958-3768

Universidad Nacional Mayor de San Marcos. Lima, Perú

Presentado: 24/08/2021 - Aceptado: 31/08/2021 - Publicado: 23/12/2021

(C) Los autores. Este artículo es publicado por la revista Gestión en el Tercer Milenio de la Facultad de Ciencias Administrativas Universidad Nacional Mayor de San Marcos. Este es un artículo de acceso abierto, distribuido bajo los términos de la licencia Creative Commons Atribución 4.0 Internacional (CC BY 4.0) [https://creativecommons.org/licenses/by/4.0/deed.es] que permite el uso, distribución y reproducción en cualquier medio, siempre que la obra original sea debidamente citada de su fuente original. 


\section{INTRODUCCIÓN}

La crisis económica y social que se está desarrollando a raíz de la pandemia de la COVID-19 tiene un fuerte impacto sistémico afectando los aspectos sociales económicos, políticos, educativos, sanitarios entre otros, generando crisis en muchos casos y en otros, oportunidades de desarrollo económico, tanto por el lado de la oferta como de la demanda. Esta situación crea como respuesta la cohesión social y la sinergia entre los países.

Gran parte de los países de América Latina y el Caribe (ALC) han reaccionado con antelación para evitar la propagación del virus, y se han venido preparando para enfrentar el profundo impacto que la crisis podría tener en términos económicos y sociales. Más allá de las medidas urgentes, que comprensiblemente van a acaparar la atención de las políticas públicas por un tiempo, cabe comenzar a pensar en algunos elementos relevantes para esta etapa COVID-19, que podría representar una oportunidad para que la industria avance en varias de las reformas estructurales que aún siguen pendientes. Entonces nos preguntamos cómo la cadena de valor que es esencialmente la creación de valor de la empresa y, por lo tanto, una piedra angular en el buen desempeño productivo, puede convertirse en una oportunidad de actualización y captura de valor en base a las nuevas necesidades que ha impuesto esta crisis sanitaria por el COVID-19.

\section{OBJETIVO DEL ARTÍCULO}

El objetivo del presente artículo es analizar e internalizar la cadena de valor como oportunidad de actualización de captación de valor y, por ende, como pilar de la productividad en el contexto del COVID-19.

\section{ARGUMENTACIÓN}

La propagación global del virus COVID-19 ha provocado un repentino aumento de la incertidumbre y rendimientos de renta variable significativamente negativos. En medio de la pandemia causada por el coronavirus en este 2020, los eventos en todo el mundo tienen el potencial de convertir la crisis de atención médica en una crisis financiera global (Bretscher et al., 2020).
La crisis sanitaria debido al COVID-19 ha cambiado a las sociedades, en su conducta, comportamiento, deseos y necesidades, por lo cual, el mercado también está cambiado, necesitándose nuevos productos y servicios. En este contexto es necesario enfocarse en las actividades primarias que "se encuentran implicadas en la creación física del producto, su venta y transferencia al comprador, así como su asistencia posterior a la venta" (Porter, 2008, p. 56). Estas actividades son la base de toda organización de bienes o servicios, que, debido a la coyuntura, aún se encuentran en proceso de reactivación económica, por lo cual el desarrollo de los procesos productivos eficientes es clave en esta nueva normalidad.

Asimismo, Krajewski et al. (2008) afirman que:

la cadena de valor es una serie interrelacionada de procesos que produce un servicio o producto que satisface a los clientes. Cada actividad de un proceso debe agregar valor a las actividades precedentes deben eliminarse los desperdicios y los costos innecesarios. (pp. 370-371)

Una cadena de valor, entonces, comprende todas las etapas de la producción, desde el diseño inicial del producto hasta su uso final. Estas tareas pueden ser realizadas por una empresa integrada verticalmente o por varias empresas, en cuyo caso cada una puede estar especializada en un solo paso o proceso de producción.

En la toma de decisiones, para mantener y proteger un negocio o empresa en el proceso de reactivación económica, es muy importante enfocarse en una estrategia a largo plazo, y la cadena de valor es una opción que no solo brinda agilidad a toda la empresa, puesto que, cada miembro de la organización al formar parte de la cadena de valor, gastará menos energía en tratar de identificar la solución idónea, habrá transparencia en todo el proceso, y se podrá entender la toma de decisiones y el porqué de estas decisiones, para luego contribuir, también, a mejorar estas decisiones. Es necesario que cada miembro de la organización comprenda los objetivos y desafíos que se enfrentan en cada eslabón de la cadena de valor (McMullen, 2020). 
El análisis de la cadena de valor es primordial al medir aspectos de las organizaciones como la productividad, el rendimiento por áreas, la gestión de calidad y la eficacia de los recursos disponibles, entre otros. Las empresas se preocupan por optimizar sus procesos internos y, elaborar productos o brindar servicios de mayor calidad. La cadena tiende a formarse en puntos donde la información sobre las especificaciones del producto o proceso puede ser formalizado y estandarizado, determinado en gran medida por factores técnicos (Jones et al., 2019).

La productividad de acuerdo a la Organización para la Cooperación y Desarrollo Económico (OCDE, 2020) es la medición de la cantidad de producción que produce un agente económico (empresa, industria, región, etc.) de una determinada cantidad de insumos. Generalmente, una mayor productividad está relacionada con mayores ganancias y salarios- determinantes de la productividad-, así como las variaciones en sus niveles y / o tasas de crecimiento, por lo cual, han sido el foco de un escrutinio intensivo tanto por parte de académicos como de los responsables políticos. La ralentización reciente del crecimiento de la productividad en muchos países de la OCDE, por ejemplo, debido a la crisis sanitaria, ha reavivado este fenómeno, añadiéndose, en algunos casos, el estrés, el miedo y la ansiedad como enemigos de la productividad.

El impacto a corto plazo de COVID-19 se siente de inmediato y sin esfuerzo, debido al bloqueo generalizado y las medidas de distanciamiento social de manera global. Sin embargo, la pandemia terminará, dejando profundos impactos económicos, sociales, políticos y culturales (He y Harris, 2020).

En nuestro país, en los tres primeros meses del 2021, la actividad económica registró una tasa de crecimiento interanual de 3,8\%, una cifra mayor a lo esperado. No obstante, su recuperación se moderó en el trimestre previo debido a la cuarentena focalizada en el mes de febrero. Las expectativas de inflación a 12 meses se incrementaron de $2,11 \%$ a 2,43\% en el mismo periodo de tiempo. Y también se proyectaba una inflación debido a los efectos transitorios de la oferta como el aumento de precios de combustibles, algunos alimentos y tipo de cambio, de acuerdo al informe del Banco Central de Reserva del Perú (BCRP, 2021).

Las políticas asumidas por el gobierno central para enfrentar esta crisis se sustentaron fundamentalmente en el Decreto de Urgencia № 029-2020: financiamiento a la micro y pequeña empresa. Asimismo, se creó el Fondo de Apoyo Empresarial a la MYPE (FAE-MYPE) para garantizar los créditos de capital de trabajo y para reestructurar y refinanciar sus deudas; también se creó el FAE Turismo, el FAE agrícola. Igualmente, se liberó la cuenta Compensación por Tiempo de Servicios (CTS) hasta el retiro de 2400 soles, así como la transferencia de 200 millones de soles para todos los 1874 municipios provinciales y distritales para adquirir y distribuir una canasta básica familiar a la población vulnerable, entre otras. Y el programa Reactiva Perú con una vigencia de cuatro años, el cual se complementa con el Fondo de Apoyo Empresarial para las microempresas, alcanzando un total de 800 millones, con el fin de apalancar alrededor de 4 mil millones de soles para ayudar a dichas empresas (Parlamento Andino, 2021).

Es importante destacar, que en el Perú se promulgó el 02 de julio del 2013 la vigente Ley № 30056 - Ley que modifica diversas leyes para facilitar la inversión, impulsar el desarrollo productivo y el crecimiento empresarial, cuyo objetivo primordial establecer el marco legal para la promoción de la competitividad, formalización y el desarrollo de las micro, pequeñas y medianas empresas (mipyme) (El Peruano, 2013). En base a esta Ley, la clasificación para las Micro, Pequeñas y Medianas empresas se aprecia en la Tabla 1.

Tabla 1

Cuadro comparativo: clasificación para las Micro, Pequeñas y Medianas empresas

\begin{tabular}{lcccc}
\hline & \multicolumn{2}{c}{ Ley MYPE D.S. № 007-2008-TR } & \multicolumn{2}{c}{ Ley № 30056 } \\
\hline & Ventas anuales & Trabajadores & Ventas anuales & Trabajadores \\
\hline Microempresa & Hasta 150 UIT & 1 a 10 10 & Hasta 150 UIT & No hay límites \\
Pequeña empresa & Hasta 1,700 UIT & 1 a 100 & Hasta 150 UIT y hasta 1,700 UIT & No hay límites \\
Mediana empresa & & & Más de 1,700 UIT y hasta 2,300 UIT & No hay límites \\
\hline
\end{tabular}

Nota. Elaboración propia. 
Podemos observar que la reactivación económica está aún en proceso. Por ejemplo, enfocándonos en las pequeñas y medianas empresas (PYMES), en base a lo manifestado por Belas et al. (2014) como se citó en Strakova et al. (2021) estas son propensas a mayores riesgos comerciales porque son sensibles a los cambios en el ambiente de negocios y su productividad se ve afectada por obstáculos, a pesar del hecho de que representan una contribución al crecimiento económico, el empleo y la competitividad de un país. A este contexto, se añade, por ejemplo, que debido a la inestabilidad del mercado, la informalidad y los productos nuevos o sustitutos que se comercializan en el mercado, es necesario e importante que se analice la cadena de valor como "la herramienta básica que permite disgregara a la empresa en sus actividades estratégicas relevantes para comprender el comportamiento de los costos y las fuentes de diferenciación existentes y potenciales" (Porter, 2008, p. 51).

En estos momentos lo primordial es aliviar el impacto económico de la pandemia, particularmente para apoyar a las microempresas, pequeña y mediana empresa con el fin de proteger las fuentes de empleo, y sentar las bases para una sólida recuperación económica. De acuerdo al BCRP (2020) en relación a la oferta, se debe implementar un plan adecuado de reanudación de las actividades y las empresas deben adaptarse a los nuevos entornos de negocios, especialmente los sectores no primarios.

De acuerdo con el Ministerio de la Producción, en el 2019, se estima que existen aproximadamente dos millones de micro, pequeñas y medianas empresas (mipymes) en nuestro país, las cuales representan el $99.5 \%$ del tejido empresarial nacional y son las que generan empleo, por eso se les llama también el motor de la economía; puesto que son responsables del empleo del $90 \%$ de la población económicamente activa del sector privado (El Peruano, 2019).

Zhang (2020) sugiere que los empresarios o altos directivos de este tipo de empresas deben transformar la concepción de sus negocios para llevar a cabo una cooperación abierta basada en la cadena de valor, diseñar el mecanismo de acoplamiento de beneficios como garantía para la separación y reorganización de la cadena de valor para adquirir recursos, y formular el método de separación de la cadena de valor. y reorganización según la propia situación de la empresa. Por lo cual, se debe continuar con una productividad que sea trabajar de forma más inteligente, no en trabajar más intensamente, lo que significa desarrollar la capacidad de producir más mediante la mejora de la organización de los factores de producción con nuevas ideas, innovaciones tecnológicas y nuevos modelos de negocio (OECD, 2015).

La cadena de valor de una empresa gráfica las actividades de manera independiente. En la realidad estas actividades no son independientes, ya que interactúan con otras cadenas de valor (proveedores, empresa y clientes). Una vez analizada la cadena de valor de la empresa e identificadas las principales fuentes de ventaja competitiva, se debe optar por una estrategia que permita el cumplimiento de la misión y de los objetivos estratégicos teniendo en cuenta, la influencia y la tendencia del entorno. En el contexto normal del desarrollo de una empresa o negocio, el análisis de la cadena de valor tiene como objetivo principal identificar sus fortalezas y debilidades y de esta manera lograr ventajas competitivas que permitan desarrollarse en el mercado que en estos momentos esta lentamente regresando a sus actividades.

El análisis de la cadena de valor en una empresa permite realizar un diagnóstico situacional en cuanto a la capacidad de generación de valor para la empresa, midiendo su margen a través de la productividad, que está representado la calidad y la rentabilidad, extendiéndose ese valor al comprador (cliente).

\section{CONCLUSIONES}

La optimización de la cadena de valor es importante en la empresa para redefinir sus procesos, permite una colaboración más profunda, reduce las fugas de valor y mantiene la productividad y la innovación. Esta crisis sanitaria es una gran oportunidad de actualización y captura de valor y es necesario tener en cuenta que se necesita garantizar el empleo, y la preocupación por la salud física y mental.

La cadena de valor constituye una herramienta estratégica para incrementar el nivel de competitividad y productividad en una empresa. 
Podría inferirse que la productividad asociada a la calidad y a la rentabilidad forman la cadena de valor de una organización permitiéndole obtener una ventaja competitiva en el sector de su competencia.

En estos momentos las empresas deben fortalecer sus herramientas de gestión con el fin de garantizar una transición fluida y segura, por ejemplo, a las plataformas digitales, que exigen estos nuevos escenarios. La sostenibilidad es clave para el futuro de cualquier negocio; cuando regrese la normalidad, cualquiera que sea esa "nueva normalidad", desde ahora hay que enfocarse en estrategias, cuyos objetivos principales sean lograr la sostenibilidad y rentabilidad que permita que el nivel de productividad en bienes o servicios sea eficiente como fundamento del mejor o máximo rendimiento, optimizando los recursos de la organización.

\section{REFERENCIAS BIBLIOGRÁFICAS}

Banco Central de Reserva del Perú. (junio de 2020). https://www.bcrp.gob.pe/docs/Publicaciones/Reporte-Inflacion/2020/junio/reporte-de-inflacion-junio-2020.pdf

Banco Central de Reserva del Perú. (junio de 2021). Reporte de Inflación junio 2020. https://www. bcrp.gob.pe/docs/Publicaciones/Reporte-Inflacion/2021/junio/reporte-de-inflacion-junio-2021.pdf

Bretscher, L., Hsu, A., Simasek, P., y Tamoni, A. (2020). The Supply Channel of Uncertainty Shocks and the Cross-Section of Returns: Evidence From the COVID-19 Crisis. Georgia Tech Scheller College of Business Research Paper No. 3588418, 1-42. http://doi.org/10.2139/ssrn.3588418

El Peruano. (2013). Ley que modifica diversas leyes para facilitar la inversión, impulsar el desarrollo productivo y el crecimiento empresarial. Lima. El Peruano. https://busquedas. elperuano.pe/normaslegales/ley-que-modifica-diversas-leyes-para-facilitar-la-inversion-ley-n-30056-956689-1/

El Peruano. (julio de 2019). Cuatro características de las mipymes peruanas. El Peruano. https:// elperuano.pe/noticia/81246-cuatro-caracteristicas-de-las-mipymes-peruanas\#: :text $=$ De $\% 20$ acuerdo $\% 20$ con $\% 20$ el $\% 20$ Ministerio,99.5\%25\%20del $\% 20$ tejido $\% 20$ empresarial\%20nacional.\&text=El\%20Produce $\% 20$ indica $\% 20$ que $\% 20$ solo, acceso $\% 20$ al\%20sistema\%20financiero\%20re
He, H., y Harris, L. (2020). The impact of Covid-19 pandemic on corporate social responsibility and marketing philosophy. Journal of Business Research, 176 -182. https://doi.org/10.1016/j. jbusres.2020.05.030

Jones, L., Demirkaya, M., y Bethmann, E. (2019). Global Value Chain Analysis: Concepts and Approaches. Journal of International Commerce and Economics, 1-29.

Krajewski, L., Ritzman, L., y Malhotra, M. (2008). Administración de operaciones (8 ed.). Pearson.

McMullen, J. (2020). Managing risk and uncertainty: The importance of optimizing your value chain. HP Business Trends, 9-11.

Organisation for Economic Co-operation and Development. (julio de 2015). El Futuro de la Productividad. http://www.oecd.org/economy/growth/El-futuro-de-la-productividad.pdf

Organisation for Economic Co-operation and Development. (enero de 2020). Productivity definition andmeasurement.http://web.b.ebscohost.com/ ehost $/ \mathrm{pdfviewer} / \mathrm{pdf}$ viewer?vid=0\&sid=da3c3ee6-2f75-400e-bc5f-c6ab01627f02\%40pdc-v-sessmgr05

Parlamento Andino. (junio de 2021). Actualidad Informes COVID. https://www.parlamentoandino. org/images/actualidad/informes-covid/Peru/ Principales-medidas-adoptadas-por-el-gobierno-peruano.pdf

Porter, M. (2008). Ser Competitivo (5 ed.). DEUSTO.

Strakova, J., Simbrenova, I., Partlova, P., Vachal, J., \& Zich, R. (2021). The Value Chain as the Basis of Business Model Design. Journal of Competitiveness, 13(2), 135-151. https://doi.org/10.7441/ joc.2021.02.08

Zhang, G. (2020). Research on the Acquisition of Development Resources and Capabilities of SMEs: Based on the Perspective of Value Chain Separation and Reorganization. Industrial Engineering and Innovation Management, 91-96. https://doi.org/10.23977/ieim.2020.030203 